\title{
Heat shock protein expression in umbilical artery smooth muscle
}

\author{
C. M. Brophy $y^{1,3,4}$, A. Beall ${ }^{1,3,4}$, K. Mannes', S. Lamb ${ }^{1,3,4}$, M. Dickinson ${ }^{1,3,4}$, D. Woodrum ${ }^{1,3}$ \\ and L. D. DeVoe ${ }^{2}$ \\ Departments of 'Surgery, 'Obstetrics and Gynecology, and 'Medicine (The Institute for Molecular Medicine and Genetics), \\ Medical College of Georgia, 1120 15th Street, Augusta, GA 30912, USA; and 'The Augusta Veterans Administration Medical Center, \\ Augusta, GA30901, USA
}

\begin{abstract}
Postpartum vasospasm in the umbilical arteries may be due to impaired vasorelaxation secondary to alterations in the expression of heat shock proteins. The contractile responses of pre- and full-term bovine umbilical artery smooth muscles were determined in a muscle bath. Heat shock protein expression was determined in bovine and human arterial tissues using western blotting with specific antisera. Full-term bovine and human umbilical artery smooth muscle was refractory to relaxation induced by the nitric oxide donor, sodium nitroprusside. This impaired vasorelaxation was associated with the expression of the inducible form of the heat shock protein, HSP70i, and increases in the expression of the small heat shock protein, HSP27. Small heat shock proteins have been implicated in modulating contraction and relaxation responses in vascular smooth muscles. Thus, alterations in heat shock protein expression may play a role in umbilical artery vasospasm.
\end{abstract}

\section{Introduction}

Vasospasm in the umbilical vasculature is essential for the conversion from the placental-fetal circulation to the neonatal circulation. Two major hypotheses have emerged to explain vasospasm in the umbilical vessels after parturition: the loss of prostanoids, which sustain vasorelaxation; and the increase in oxygen tension in the arterialized blood passing through the umbilical arteries (Etherington, 1967; Karim et al., 1997). While vasodilating prostanoids induce vascular relaxation by activation of adenylate cyclase, the umbilical artery smooth muscle is refractory to relaxation by adenylate cyclase activators (Renowden et al., 1992; Bergh et al., 1995). Vasospasm must occur in both the umbilical arteries and veins and, although the oxygen tension increases in the arteries after birth (Wulf et al., 1964), it is unlikely that it increases in the vein. Therefore, the specific mechanisms that initiate the intense vasospasm in the umbilical vasculature after birth have not been established.

Heat shock proteins (HSPs) are a group of phylogenetically well conserved proteins that may have pivotal roles in the adaptation to physiological stress (Welch et al., 1986). Although the specific cellular functions of HSPs are not completely understood, some of the HSPs are constitutively present in mammalian tissues, which suggests they play a role in normal physiological processes. Heat shock proteins have been implicated in the mediation of smooth muscle contraction and relaxation responses (Bitar

Received 1 December 1997 et al., 1991; Beall et al., in press). Since the final effector cell in any vasospastic process is the vascular smooth muscle, it is hypothesized that HSPs are induced during parturition and, thereby, influence the process of umbilical artery vasospasm.

\section{Materials and Methods}

\section{Materials}

Electrophoresis reagents and the DC protein assay kit were from BioRad (Hercules, CA). Mouse anti-HSP70 antibody was from Amersham (RPN 1197) and mouse antiHSP27 was a generous gift from M. Welsh (University of Michigan, Ann Arbor, MI) (Welsh et al., 1996). All other reagents were of analytical grade.

\section{Preparation of vascular smooth muscle strips}

Full-term umbilical cords were obtained from the Labor and Delivery suite at the Medical College of Georgia under a protocol approval by the institutional Human Assurance Committee. Only cords obtained from normal deliveries from healthy women were used in this study.

Pre-term bovine umbilical cords were obtained from an abattoir (Shapiro's Meatpackers, Augusta, GA). The gestational age of the calves was approximated by weight and arbitrarily placed into a trimester scale. Calves $<22 \mathrm{~kg}$ were considered first trimester; $22-44 \mathrm{~kg}$, second trimester; and $>88 \mathrm{~kg}$, third trimester. Full-term bovine umbilical cords 
were obtained from local farmers at assisted births. The umbilical arteries were placed in cold physiological saline solution (10 mmol $N$-2-hydroxyethylpeperazine- $N^{\prime}-2$ ethanesulfonic acid $\mathrm{l}^{-1}$ (Hepes), $140 \mathrm{mmol} \mathrm{NaCl} \mathrm{l}^{-1}, 4.7 \mathrm{mmol}$ $\mathrm{KCl} \mathrm{l}^{-1}, 1.0 \mathrm{mmol} \mathrm{MgSO} \mathrm{l}^{-1}, 1.0 \mathrm{mmol} \mathrm{NaH}_{2} \mathrm{PO}_{4} \mathrm{l}^{-1}, 1.5 \mathrm{mmol}$ $\mathrm{CaCl}_{2} \mathrm{I}^{-1}, 10 \mathrm{mmol}$ glucose $\mathrm{I}^{-1}, \mathrm{pH}$ 7.4) for transport and storage. At the laboratory, the umbilical arteries were dissected from the cords and the endothelial layer was gently denuded with a cotton-tipped applicator. The arteries were opened longitudinally and thin transverse strips were cut.

\section{Contractile physiology}

Transverse sections $(1 \mathrm{~mm})$ of umbilical artery smooth muscles were mounted in a tissue bath with 3-0 silk suture. One end was anchored to a fixed glass pipette and the other to a force transducer (Grass Instrument Corp., Quincy, MA). Tension was recorded on a strip-chart recorder (Gould Instrument Corp., Norcross, GA). Strips were equilibrated for $60 \mathrm{~min}$ in water jacketed chambers at $37^{\circ} \mathrm{C}$ containing Krebs-bicarbonate buffer (KRB, $120 \mathrm{mmol} \mathrm{NaCl} \mathrm{1}^{-1}, 4.7 \mathrm{mmol}$ $\mathrm{KCl} \mathrm{l}^{-1}, 1.0 \mathrm{mmol} \mathrm{MgSO}_{4} \mathrm{I}^{-1}, 1.0 \mathrm{mmol} \mathrm{NaH}_{2} \mathrm{PO}_{4} \mathrm{l}^{-1}, 10 \mathrm{mmol}$ glucose $\mathrm{l}^{-1}, 1.5 \mathrm{mmol} \mathrm{CaCl}_{2} \mathrm{l}^{-1}$, and $25 \mathrm{mmol} \mathrm{Na}_{2} \mathrm{HCO}_{3} \mathrm{l}^{-1}$ ). The strips were gassed with $95 \% \mathrm{O}_{2}-5 \% \mathrm{CO}_{2}$ and maintained at $\mathrm{pH} 7.4$. Some strips were gassed with $95 \% \mathrm{~N}_{2}-5 \% \mathrm{CO}_{2}$. The maximal contractile length was adjusted with repeated additions of $110 \mathrm{mmol} \mathrm{KCl}^{-1}$ (with equimolar replacement of $\mathrm{NaCl}$ ). After re-equilibration, the strips were precontracted with a submaximal dose of 5-hydroxytryptamine $\left(1 \mathrm{mmol} \mathrm{I}^{-1}\right)$, and the cumulative dose-dependent relaxation response to the NO donor, sodium nitroprusside (SNP), was determined. The data are reported as the percentage of relaxation to each dose of SNP. Serotonin and SNP were diluted in water and added directly to the muscle bath.

\section{Immunoblotting}

Umbilical artery smooth muscles were homogenized in 60

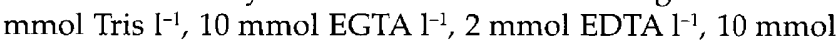
$\beta$-mercaptoethanol $\mathrm{l}^{-1}, 5 \mathrm{mg}$ Aprotinin $\mathrm{ml}^{-1}, 250 \mathrm{mmol}$ Leupeptin $\mathrm{l}^{-1}, 1 \mathrm{mmol}$ benzamidine $\mathrm{l}^{-1}, \mathrm{pH}$ 7.4. The samples were centrifuged at $10000 \mathrm{~g}$ for $10 \mathrm{~min}$ and the supernatant was protein normalized. The proteins were separated on SDS-PAGE gels and transferred to Immobilon-P (Millipore, Bedford, MA). The blots were blocked with $5 \%$ milk in 10 mmol Tris $\mathrm{l}^{-1}, 150 \mathrm{mmol} \mathrm{NaCl} \mathrm{l}^{-1}, 0.5 \%$ Tween-20, $\mathrm{pH} 7.4$ (TBS) for $1 \mathrm{~h}$. The blots were incubated with mouse anti-HSP70 antibodies (1:5000 dilution in TBS, 5\% milk) or mouse anti-HSP27 antibodies (1:4000 dilution in TBS, 5\% milk) for $3 \mathrm{~h}$ at $4^{\circ} \mathrm{C}$. The blots were then washed in TBS, $0.5 \%$ Tween 20 (three washes of $5 \mathrm{~min}$ ). Immunoreactive spots were detected using donkey anti-mouse horse-radish peroxidase for $1 \mathrm{~h}$ at $25^{\circ} \mathrm{C}$ and, after washing (eight washes of $5 \mathrm{~min}$ in TBS), western blot chemiluminescence reagent was applied (Dupont NEN, Boston, MA) and the blots were developed with Kodak XAR film.

\section{HSP27 quantitation}

Human umbilical artery smooth muscle or bovine carotid artery smooth muscles were homogenized in $25 \mathrm{mmol}$ Hepes $\mathrm{l}^{-1}, 150 \mathrm{mmol} \mathrm{NaCl} \mathrm{l}^{-1}, 10 \mathrm{mmol}$ EDTA $\mathrm{l}^{-1}, 1 \mathrm{mmol}$ DTT $\mathrm{l}^{-1}$, 2 mmol benzamidine $\mathrm{l}^{-1}, \mathrm{pH}$ 7.4. The samples were centrifuged at $10000 \mathrm{~g}$ for $10 \mathrm{~min}$ and the supernatants were protein normalized. Arterial homogenates containing $10 \mathrm{mg}$ protein were dot blotted onto nitrocellulose. The blots were fixed with $20 \%$ methanol, dried, blocked with TBS, $5 \%$ milk for

$1 \mathrm{~h}$, washed three times with TBS, $0.5 \%$ Tween, and then probed with anti-HSP27 antibodies (1:4000 dilution in TBS, $5 \%$ milk) for $1 \mathrm{~h}$. The blots were washed six times with TBS, $0.5 \%$ Tween and then probed with ${ }^{125} \mathrm{I}$ goat anti-mouse IgG.

\section{Two-dimensional electrophoresis}

Strips of carotid and umbilical arteries were equilibrated for $60 \mathrm{~min}$ in bicarbonate buffer. The tissue was crushed using a mortar and pestle under liquid $\mathrm{N}_{2}$. The powder was resuspended in $9 \mathrm{~mol}$ urea $\mathrm{1}^{-1}, 2 \% 3$-[3-cholamidopropyl dimethylammonio]-1-propanesulfonate (chaps), $100 \mathrm{mmol}$ dithithreitol $1^{-1}$, and the proteins were separated by twodimensional gel electrophoresis. Protein $(150 \mu \mathrm{g})$ was loaded onto an isoelectric focusing (IEF) slab gel with $2 \%(\mathrm{v} / \mathrm{v})$ ampholytes (1.0 part $\mathrm{pH} 3.5-10,1.5$ parts $\mathrm{pH} 5-7$, and 2.5 parts $\mathrm{pH}$ 6-8, LKB Pharmacia, Uppsala) and electrophoresis was performed for $1 \mathrm{~h}$ at $100 \mathrm{~V}, 1 \mathrm{~h}$ at $200 \mathrm{~V}$, and $19 \mathrm{~h} 24 \mathrm{~min}$ at $500 \mathrm{~V}$. The IEF lanes were placed on SDS-PAGE gels $(12 \%)$ and run for $21 \mathrm{~h}$ at $90 \mathrm{~V}$. The gels were transferred to Immobilon and stained with Aurodye Forte (Amersham, Arlington Heights, IL), a dye for quantitative protein detection.

\section{Statistical analysis}

Densitometric analysis of the phosphoproteins was performed using a PhosphorImager and ImageQuant software (Molecular Dynamics, Sunnyvale, CA). The results are depicted as means \pm SEM. Statistical analysis was by oneway analysis of variance followed by the Tukey's test using SigmaStat software (Jandel Scientific, San Rafael, CA) and $P<0.05$ was considered significant.

\section{Results}

\section{Full term bovine umbilical artery smooth muscle is refractory to $\mathrm{NO}$-dependent vasorelaxation}

Strips of bovine umbilical artery smooth muscle were equilibrated in a muscle bath and, after pre-contraction with $1 \mu \mathrm{mol}$ serotonin $1^{-1}$, the cumulative dose-dependent relaxation response to the NO donor, sodium nitroprusside (SNP), was determined. There were no differences in bovine umbilical artery smooth muscle relaxation responses in umbilical cords obtained from animals in the first, second, or 


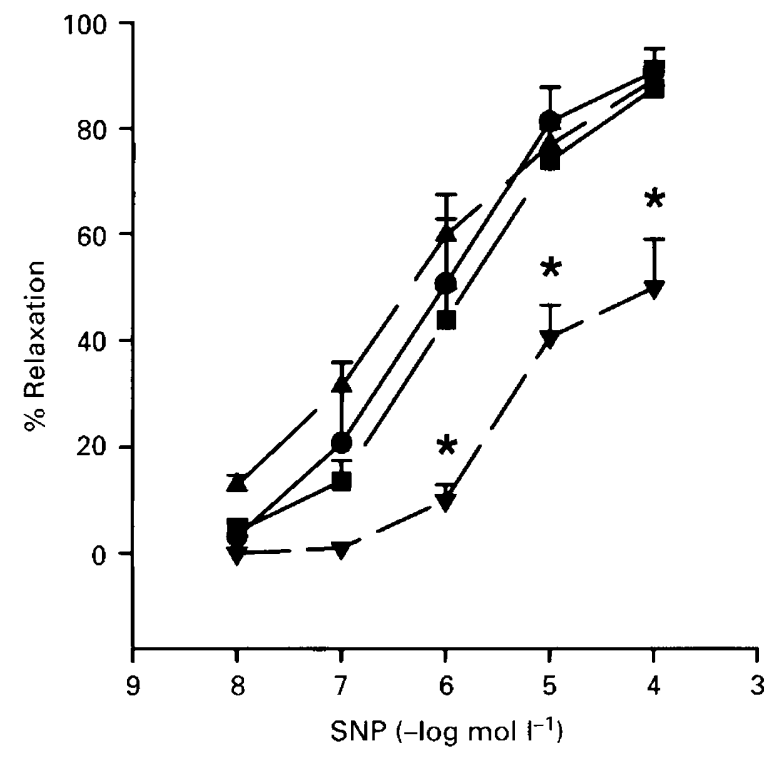

Fig. 1. Nitric oxide-dependent relaxation responses in bovine umbilical artery smooth muscle. Strips of bovine umbilical artery smooth muscle from pre- and full-term bovine umbilical cords were equilibrated in a muscle bath under low $\left(95 \% \mathrm{~N}_{2}-5 \% \mathrm{CO}_{2}\right)$ and high $\left(95 \% \mathrm{O}_{2}-5 \% \mathrm{CO}_{2}\right) \mathrm{O}_{2}$ tensions. The strips were pre-contracted with $1 \mu \mathrm{mol}$ 5-hydroxytryptamine $\mathrm{l}^{-1}$ and the cumulative dose-dependent relaxation responses to the NO-donor, sodium nitroprusside (SNP), were determined. There were no differences in the relaxation responses of bovine umbilical artery smooth muscles from cords obtained from first $(\mathbf{\Delta})$, second $(\boldsymbol{\bullet})$ or third $(\boldsymbol{\square})$ trimester calves. Neither were there differences in the relaxation responses of preterm bovine umbilical artery smooth muscles equilibrated under low or high $\mathrm{O}_{2}$ tensions (data not shown). The relaxation response of full-term bovine umbilical artery smooth muscles $(\boldsymbol{\nabla})$ to SNP $\left(10^{-6}-10^{-4} \mathrm{~mol} \mathrm{l}^{-1}\right)$ was significantly less than the relaxation response of pre-term bovine umbilical artery smooth muscles to SNP $(n=5-8$, $* P<0.05$, ANOVA). third trimesters (Fig. 1). There was also no difference in the relaxation responses of bovine umbilical smooth muscles equilibrated under low $\mathrm{O}_{2}$ tensions $\left(95 \% \quad \mathrm{~N}_{2}-5 \% \quad \mathrm{CO}_{2}\right)$ compared with high $\mathrm{O}_{2}$ tensions $\left(95 \% \mathrm{O}_{2}-5 \% \mathrm{CO}_{2}\right)(n=5$, $P>0.05$, ANOVA, data not shown). However, full-term bovine umbilical cords, obtained from spontaneous normal deliveries, displayed a dose-dependent relaxation response that was shifted to the right (Fig. 1). In addition, full-term human umbilical artery smooth muscle did not relax in response to sodium nitroprusside $\left(10^{-8}-10^{-3} \mathrm{~mol} \mathrm{SNP}^{-1}\right.$, $n=8$, data not shown).

\section{Inducible form of HSP70 is present in human umbilical artery smooth muscle but not bovine carotid artery smooth muscle}

Western blots with antibodies that specifically recognize the inducible form of HSP70 (HSP70i) demonstrated that an immunoreactive band of $M_{r} 70 \mathrm{kDa}$ was present in human umbilical artery smooth muscle (Fig. 2). HSP70i was not present in a vascular smooth muscle that displays normal relaxation physiology, bovine carotid artery smooth muscle (Fig. 2), or in human saphenous vein (data not shown). However, HSP70i was inducible in bovine carotid artery smooth muscle by stressors such as norepinephrine $(10 \mu \mathrm{mol}$ $\left.1^{-1}\right)$ or sodium arsenite $\left(500 \mu \mathrm{mol} \mathrm{l^{-1 }}\right)$, suggesting that the antibodies recognized bovine HSP70i (Fig. 2).

\section{Inducible form of HSP70 is present in full-term bovine umbilical artery smooth muscle but not pre-term bovine umbilical artery smooth muscle}

Western blots using anti-HSP70i demonstrated a strongly immunoreactive band of $M_{\mathrm{r}} 70 \mathrm{kDa}$ in full term bovine
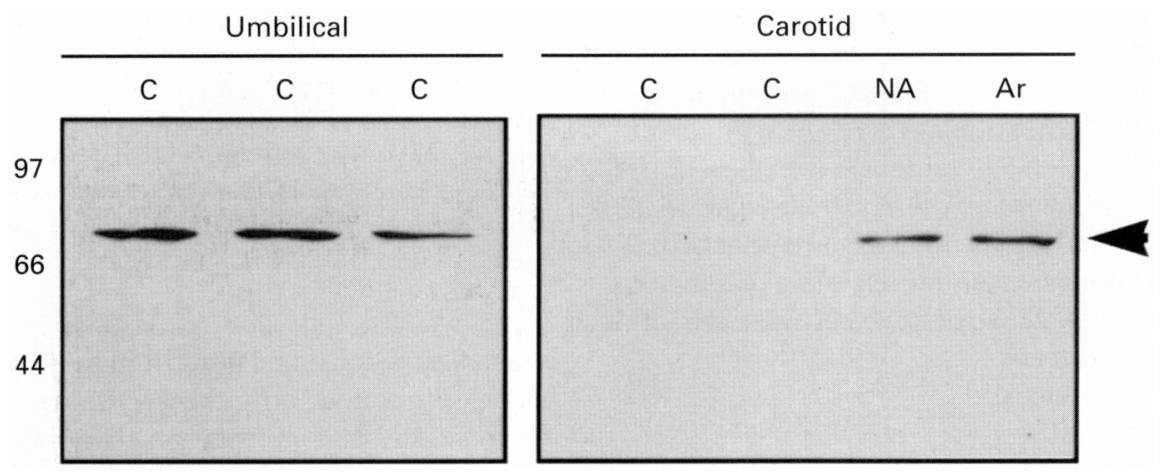

Fig. 2. Immunoreactive HSP70 in human umbilical artery smooth muscle. Strips of human umbilical artery or bovine carotid artery smooth muscle were homogenized and the $10000 \mathrm{~g}$ supernatants were separated on 10\% SDS-PAGE gels and transferred to lmmobilon (C). Some strips of bovine carotid artery smooth muscle were treated with noradrenaline (NA, $10 \mu \mathrm{mol}$ $\mathrm{1}^{-1}$ for $30 \mathrm{~min}$ ) or arsenite (Ar, $500 \mu \mathrm{mol} \mathrm{l}^{-1}$ for $30 \mathrm{~min}$ ) $6 \mathrm{~h}$ before homogenization. Immunoreactive bands of $M_{r} 70 \mathrm{kDa}$ (arrowhead) were present in all human umbilical artery smooth muscles examined ( $n=12$, only three representative samples are shown on the figure). Although immunoreactive bands were not detected in homogenates of bovine carotid artery smooth muscle, stimulation with noradrenaline or arsenite induced a band of $M_{r} 70 \mathrm{kDa}$ in carotid homogenates. 


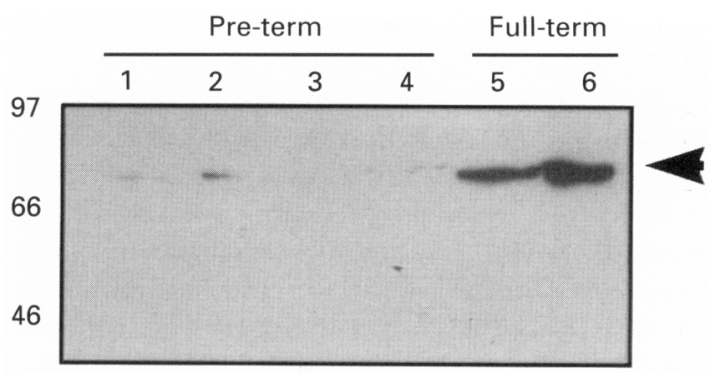

Fig. 3. Immunoreactive HSP70 in full-term bovine umbilical artery smooth muscle. Strips of pre- or full-term bovine umbilical artery smooth muscles were homogenized and the $10000 \mathrm{~g}$ supernatants were separated on $10 \%$ SDS-PAGE gels and transferred to Immobilon. Immunoreactive bands of $M_{\mathrm{r}} 70 \mathrm{kDa}$ (arrowhead) were present in all full-term umbilical artery smooth muscles examined ( $n=4$, only two representative samples are shown on the figure). There were only weakly immunoreactive bands for HSP70 $i$ in umbilical artery smooth muscles from pre-term bovine cords $(n=4)$. Densitometric analysis revealed significantly more HSP70 $i$ in full-term compared with preterm cords $(2.1 \pm 0.5$ versus $14.4 \pm 1.3, P<0.05$, Mann-Whitney rank sum test, $n=4$ ).

umbilical artery smooth muscle homogenates (Fig. 3). In western blots of pre-term umbilical artery smooth muscle, there was only a very weakly immunoreactive band at $M_{\mathrm{r}}$ $70 \mathrm{kDa}$.

\section{HSP27 in umbilical artery smooth muscle compared with bovine carotid artery smooth muscle}

Immunoblotting with antibodies specific for the small heat shock protein, HSP27, demonstrated a single immunoreactive band in homogenates of bovine carotid and human umbilical artery smooth muscle (Fig. 4). Using anti-HSP27 antibodies and a dot blotting technique, HSP27 was quantitated in homogenates of umbilical and carotid arteries. There was significantly more immunoreactive HSP27 in homogenates of human umbilical smooth muscles than in bovine carotid smooth muscles (Fig. 4). The amount of HSP27 protein present on two-dimensional gels was quantitated to confirm this result. There was significantly more HSP27 protein in umbilical artery homogenates than in carotid artery homogenates $(28.8 \pm 3.3$ versus $1.8 \pm 0.4, n=4, P<0.05$ ). Insufficient amounts of fullterm bovine umbilical artery smooth muscle were obtained to quantitate differences in HSP27 expression between pre- and full-term bovine umbilical artery.

\section{Discussion}

The present study demonstrates the activation of the stress response umbilical artery smooth muscle from human and bovine full-term umbilical cords. The inducible form of HSP70 (HSP70i) was present in full-term umbilical artery smooth muscle from both human and bovine umbilical cords (Figs 2 and 3). In addition, while HSP70i was not present in normal vascular smooth muscle (bovine carotid artery smooth muscle), immunoreactive HSP70i could be induced
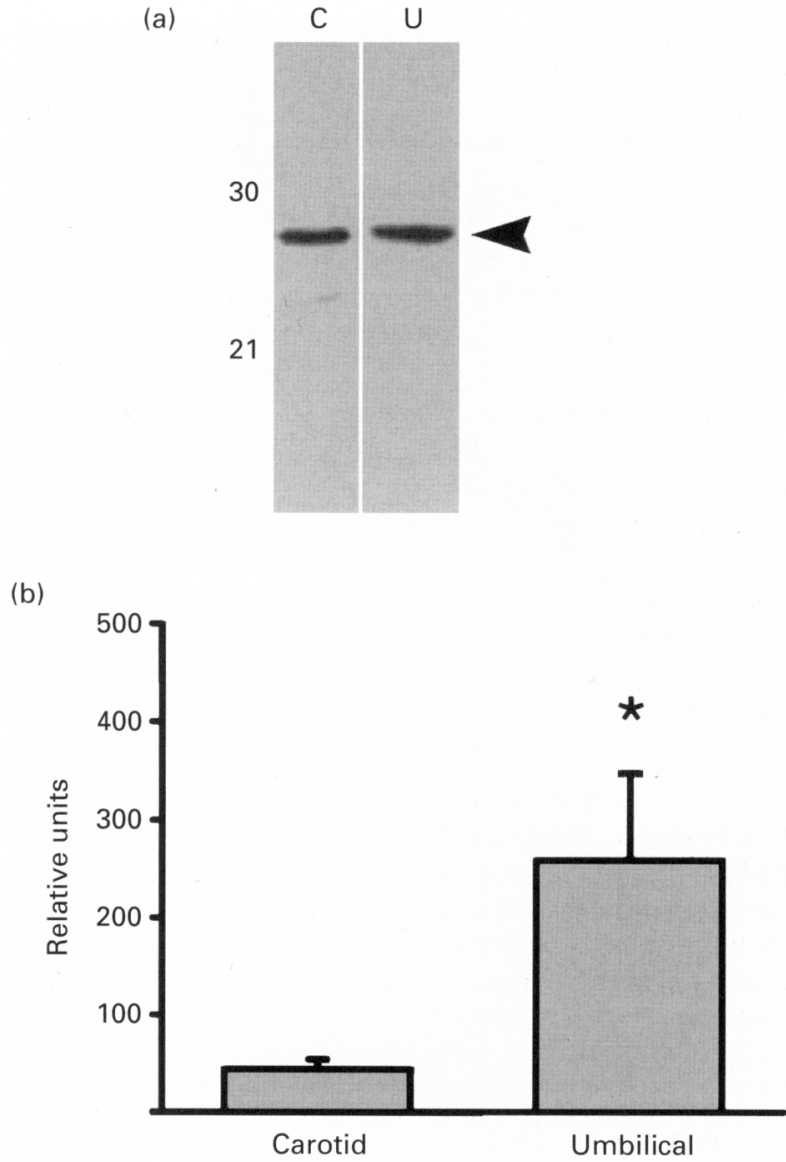

Fig. 4. Quantitation of HSP27 expression in human umbilical artery smooth muscle. Human umbilical artery smooth muscle or bovine carotid artery smooth muscles were homogenized and the $10000 \mathrm{~g}$ supernatants were protein normalized. (a) Western blots revealed a single immunoreactive band using anti-HSP27 antibodies in both carotid $(C)$ and umbilical $(U)$ homogenates. This led to the use of a dot blot method to quantitate HSP27 immunoreactivity in the homogenates. Arterial homogenates containing $10 \mu \mathrm{g}$ total protein were dot blotted onto nitrocellulose and probed with anti-HSP27 antibodies and then with ${ }^{125}$ I-labelled goat anti-mouse IgG secondary antibodies. The amount of immunoreactive protein (relative units) was determined using a PhosphorImager. (b) There was significantly more immunoreactive $\mathrm{HSP} 27$ in homogenates of human umbilical arteries (U) than in homogenates of bovine carotid arteries $(C)(n=6-10, * P<0.05$, ANOVA $)$.

by stressors such as noradrenaline and sodium arsenite. Using a limited amount of tissue, it was possible to demonstrate that immunoreactive HSP70 $i$ was present in full-term bovine umbilical artery smooth muscle but not preterm bovine umbilical artery smooth muscle. Finally, there was more immunoreactive HSP27 in human umbilical artery smooth muscle than in bovine carotid artery smooth muscle.

The expression of HSPs in umbilical artery smooth muscle was associated with impaired sodium nitroprusside dependent relaxation responses in full-term umbilical arteries (Fig. 1) (Renowden et al., 1992; Bergh et al., 1995). There were no differences in relaxation responses in umbilical artery smooth muscles from bovine umbilical 
cords at different stages of gestation. There were also no differences in the relaxation responses at low $\left(95 \% \mathrm{~N}_{2}-5 \%\right.$ $\mathrm{CO}_{2}$ ) compared with at high $\left(95 \% \mathrm{O}_{2}-5 \% \mathrm{CO}_{2}\right) \mathrm{O}_{2}$ tensions. The exposure of pre-term umbilical artery smooth muscles to high $\mathrm{O}_{2}$ tensions ( $>100 \mathrm{~mm} \mathrm{Hg}$ ) did not render the muscles refractory to sodium nitroprusside-dependent relaxation, suggesting that an event in addition to increased $\mathrm{O}_{2}$ tension is necessary for umbilical artery vasospasm.

While most of the data pertaining to heat shock protein expression and function has been obtained from tissue cultures, it has recently been demonstrated that physiological restraint and surgical stress induce the expression of HSP70 selectively in vascular and adrenal tissue in rats (Udelsman et al., 1991, 1993). Restraint stress also induced an increase in the expression of HSP27 selectively in vascular tissue, and the physiological expression of HSPs in the vasculature was associated with hypertension (Blake, 1995).

The present study is the first investigation of which we are aware that shows activation of the stress response in human vascular tissue under physiological conditions. Activation of the stress response in the umbilical vasculature may contribute to vasospasm after parturition. HSP27 may mediate sustained vascular smooth muscle contraction in bombesin-stimulated smooth muscles (Bitar et al., 1991). In addition, increases in the phosphorylation of proteins with $M_{r} 27 \mathrm{kDa}$ and similar isoelectric points to HSP27 have been implicated in association with agonist-induced contraction of vascular smooth muscles (Barany et al., 1992). The thrombin-induced contraction of vascular smooth muscle has been shown to be associated with increases in the phosphorylation of HSP27 (Brophy et al., 1998). HSP27 is relatively abundant in muscle tissues and has been shown to modulate actin filament dynamics (Miron et al., 1988). In addition, increases in the phosphorylation of another small HSP, HSP20, have been implicated in mediating vascular smooth muscle relaxation (Beall et al., 1997). HSP20 does not appear to be phosphorylated in umbilical artery smooth muscles treated with sodium nitroprusside (Bergh et al., 1995). Taken together, these data support a role for the small HSPs in modulating umbilical artery vasospasm.

Although the specific stimulus for the induction of the HSPs in umbilical vascular tissue is not known, HSP27 has been identified as an oestrogen-regulated protein in human breast cancer cell lines (Faucher et al., 1993). HSP27 has been immunolocalized to the endometrium and cervix (Ciocca et al., 1983). The expression of HSP27 is regulated by hormones in the endometrium during the menstrual cycle (Ciocca et al., 1983). HSP27 has also been associated with the oestrogen receptor (Faucher et al., 1993). Thus, it has been suggested that HSP27 is transcriptionally induced by oestrogen and that it interacts with the oestrogen receptor. Oestrogen concentrations typically reach peak values at parturition (Tulchinsky et al., 1972). Therefore, the appropriate hormonal milieu needed to precondition this vascular system to induce HSP27 precedes the events of delivery.

The present study was constrained by the limited numbers of full-term bovine umbilical cords available and by the inability to obtain 'normal' pre-term human umbilical cords. However, HSP70 $i$ is not typically expressed in normal vascular tissue. Thus, these data suggest that the stress response is induced in umbilical artery tissue around the time of birth. In addition, the suggestion that HSPS have important roles in smooth muscle contraction and relaxation responses supports a role for the function of these proteins in vasospasm of the umbilical vasculature after parturition.

This work was supported by a VA Merit Review Award, C. M. Brophy was supported by an American Heart Association, Clinician Scientist Award, and K. Mannes was supported by a Medical College of Georgia, Dean's Student Research Fellowship. The authors appreciate the assistance of the nursing staff in labor and delivery for obtaining umbilical cords.

\section{References}

Barany M, Polyak E and Barany K (1992) Protein phosphorylation during the contraction-relaxation-contraction cycle of arterial smooth muscle Archives of Biochemistry and Biophysics 294 571-578

Beall AC, Kato K, Goldenring JR, Rasmussen H and Brophy CM (1997) Cyclic nucleotide-dependent vasorelaxation is associated with the phosphorylation of a small heat shock-related protein Journal of Biological Chemistry 272 $11283-11287$

Bergh CM, Brophy CM, Dransfield DT, Lincoln T, Goldenring JR and Rasmussen H (1995) Impaired cyclic nucleotide-dependent vasorelaxation in human umbilical artery smooth muscle American Journal of Physiology 268 $\mathrm{H} 202-\mathrm{H} 212$

Bitar KN, Kaminski MS, Hailat N, Cease KB and Strahler JR (1991) HSP27 is a mediator of sustained smooth muscle contraction in response to bombesin Biochemical and Biophysical Research Communications 181 1192-1200

Blake MJ, Klevay LM, Halas ES and Bode AM (1995) Blood pressure and heat shock protein expression in response to acute and chronic stress Hypertension 25 539-544

Brophy CM, Woodrum D, Dickinson $\mathbf{M}$ and Beall A (1998) Thrombin activates MAPKAP-2 kinase in vascular smooth muscle Journal of Vascular Surgery $27963-969$

Ciocca DR, Asch RH, Adams DJ and McGuire WL (1983) Evidence for modulation of a $24 \mathrm{~K}$ protein in human endometrium during the menstrual cycle Journal of Clinical Endocrinology and Metabolism 57 496-499

Etherington LG, Stoff J, Hughes T and Melmon KL (1997) Constriction of the human umbilical arteries. Interaction between oxygen and bradykinin Circulation Re'search 22 747-752

Faucher C, Capdevielle J, Canal I, Ferrara P, Mazarguil H, McGuire WL and Darbon J (1993) The 28-kDa protein whose phosphorylation is induced by protein kinase $C$ activators in MCF-7 cells belongs to the family of low molecular mass heat shock proteins and is the estrogen-regulated $24-\mathrm{kDa}$ protein Journal of Biological Chemistry $26815168-15173$

Karim SMM (1967) The identification of prostaglandins in human umbilical cord British Journal of Pharmacology $29230-237$

Renowden S, Edwards DH and Griffith TM (1992) Impaired cyclic nucleotide-mediated vasorelaxation may contribute to closure of the human umbilical artery after birth British Journal of Pharmacology 106 348-353

Tulchinsky D, Hobel CH and Yeager E (1972) Plasma estrone, estradiol, progesterone, and 17-OH-progesterone in human pregnancy American Journal of Obstetrics and Gynecology 112 1095-1100

Udelsman R, Blake MJ and Holbrook NJ (1991) Molecular response to surgical stress: specific and simultaneous heat shock protein induction in the adrenal cortex, aorta, and vena cava Surgery 110 1125-1131

Udelsman R, Blake MJ, Stagg CA, Ding-gang L, Putney DJ and Holbrook NJ (1993) Vascular heat shock protein expression in response to stress fournal of Clinical Inestigation $191465-473$

Wulf H (1964) The oxygen and carbon dioxide tension gradients in the human placenta at term American Joumal of Obstetrics and Gynecology 88 38-44

Welch WJ and Suhan JP (1986) Cellular and biochemical events in mammalian cells during and after recovery from physiologic stress Journal of Cell Biology 103 2035-2052

Welsh MJ, Wu W, Prvinen M and Gilmont RR (1996) Variation in expression of HSP27 mRNA during the cycle of the seminiferous epithelium and co-localization of HSP27 and microfilaments in sertoli cells of the rat Biology of Reproduction 55 141-151 